\title{
Attitudes toward Advertising by Lawyer's among Hong Kong Consumers
}

\author{
Kara Chan \\ Hong Kong Baptist University \\ Vivienne Leung \\ Hong Kong Baptist University \\ Lennon Tsang \\ Hong Kong Baptist University \\ Toby Yip \\ Hong Kong Baptist University
}

\begin{abstract}
A qualitative study was conducted to investigate attitudes toward advertising by lawyer's in Hong Kong. The study found that interviewees in general appreciated the information values of these advertisements. There were mixed views regarding the impact on the image of the lawyers brought about by advertising by lawyer's. Some interviewees found the advertisements helpful and hence perceive that the lwayers was now more approachable and transparent. However, some interviewees found advertising by lawyer's that use price appeal misleading. They perceived the lawyers to have become more commercialized. Interviewees expressed concern that advertising by lawyer's encourage the seeking of litigation as a preferred way of problem solving. The study informs lawyers regarding message design and media selection in the marketing of their services in a Chinese context.
\end{abstract}

Keywords: advertising by lawyer's/attorney's, cultural values, legal services, qualitative method

\section{Introduction}

Relaxation in advertising rules concerning lawyers in Hong Kong has been a recent phenomenon. It was not until 1996 that Hong Kong lawyers were allowed to advertise in any media (Williams, 1998). While historically there were a few individual cases of lawyers adopting aggressive promotional strategies (Chow, 2002; Nick, 2006, 2008), mass media advertising is still under-utilized by legal firms and professionals in the field. In Hong Kong, there were 6,782 solicitors with a current practicing certificate in 2010. Among them, 5,303 solicitors were in private practice 
working in 764 firms (The Law Society of Hong Kong, 2011a). The total advertising dollars spent on legal services in the same year was US \$29.5 million (admanGo, 2011). In other words, each practicing lawyer on average spent US\$5,600 on media advertising. About two thirds of this amount was spent on television, another 13 percent each spent on out-of-home media and the print media, and the rest on radio and other media (admanGo, 2011).

In a free market society like Hong Kong, marketing activities and advertising are considered a necessary part of the modern economy. With the twin forces of deregulation and increased competition, professional advertising is expected to be used widely to facilitate consumers' informed choice (Ellis \& Watterson, 2001). Public attitude of advertising generally in Hong Kong has been favorable. Surveys found that fifty percent of interviewees considered television advertising very good or good. Overall speaking, fifty percent of interviewees expressed liking of television advertising (Chan, 2006). The attitudes of Hong Kong consumers toward professional advertising have historically been positive. A survey found that interviewees perceive that professional advertising did not lower the favorable image enjoyed by lawyers, accountants and doctors ( $\mathrm{Au}, 1997)$. In such a market environment, what are consumers' attitudes toward advertising by lawyer's? How do they see the benefit and potential harm of advertising by lawyer's? What do they want to know from the advertising by lawyer's? Do they believe in the contents of advertising by lawyer's?

\section{Literature review}

Studies conducted in North America suggested that opposition to the use of mass media to promote legal services centers on the issue of reputation and credibility. Lawyers are concerned that advertising may diminish their professional image and dignity in the eyes of the public (Burton, 1991; Crane, 1995; Kallis \& Vanier, 1983; Moser \& Johns, 1996; Traylor \& Mathias, 1983). Besides, uncertainty about the benefits of advertising to the profession and to the consumer is another barrier to lawyer advertising (Crane, 1995). In addition, lawyers who are against advertising by lawyer's cite reasons such as an increase of unnecessary or unmerited litigation, and that such advertising tends to create jury bias (Cutler, Javalgi, \& Schimmel, 2003).

Since the relaxation of advertising restrictions in Western countries, perception of potential benefits for practicing lawyers increases (Crane, 1995). As a result, the lawyers have become more receptive toward advertising (Crane, 1995; McCann, Stem, \& Muehling, 1993). Further, advocates of advertising by lawyer's argue that professional advertising provides information to the public, allows consumers to make more informed decisions, and encourages positive competition among legal service providers (Brosnahan \& Andrews, 1980; Johnson, Yazdi, \& Gelb, 1993; Moser \& Johns, 1996; Smith \& Meyer, 1980).

A healthy development of advertising by lawyer's works toward a more balanced approach that considers both the value of fulfilling the public's information needs, the need of the professionals to maintain their professional image and ethical standard, as well as enforcing the advertising rules in a highly competitive business environment (Johnson, 2004; Hofer, 2010). 


\section{Advertising by lawyer's in Hong Kong}

In the past, lawyers in Hong Kong were not allowed to advertise their practice. Significant changes gradually occurred after England abandoned their traditional rules prohibiting advertising by lawyer's in the late 1980s' (Love \& Stephen, 1997). In the same vein, as Hong Kong's legal system bears a strong likeness to that of the United Kingdom (UK) where the Solicitors' Practice Promotion Code became effective on March 1992 in Hong Kong. This Code permitted some form of publicity, except advertising by television, radio, and cinema as well as in public places. In 1996, the Code was further amended and the prohibited media clause was removed (Williams, 1998). The 1996 version generally permits all kinds of truthful legal services advertising, provided that the lawyers not deviate from the guidelines documented in the Solicitors' Guide to Professional Conduct. Since then advertising by lawyer's on television and public transport facilities such as buses and mini-buses can be seen. In recent years, some law firms have also used the Google AdSense or web banners to attract potential clients.

According to the Professional Guide, promotional activities of lawyers should not bring the lawyers' profession into disrepute (The Law Society of Hong Kong, 2011b). The general principle is that promotion must be truthful, legal, honest, and decent. This is consistent with the ideal that professionalism is different from the unbound commercial spirits. The ethical aspiration of "dignified advertising" could be elaborated with the help of the comment of Peter Sit, Chairman of the Standing Committee on Compliance at The Law Society, "[the] aim of practice promotion is to increase the transparency of the firm, let the public know what sort of services are provided by the firm and how experienced they are in their areas of practice. Its purpose is to discourage lawyers to make more money through promotional activities” (Williams, 1998, p.33).

The professional standard all lawyers who advertise must meet is best illustrated in Mr. Paul Tse Wai-chun's case which was deemed to breach the principles of Hong Kong Solicitors' Guide to Professional Conduct, and Solicitors' Practice Promotion Code. The offensiveness was constituted by undignified acts of Mr. Tse, a solicitor of Hong Kong, done for self-promotion. The complaints were summarized by the Solicitors Disciplinary Tribunals and documented in "A solicitor Vs Law Society of Hong Kong”, (Court of Final Appeal Hong Kong SAR, 2008). Throughout a period of over nine years, extensive news coverage has informed the public how and why the legal community found Mr. Tse's promotional activities was unbefitting a lawyer. The offensive behaviors included his nude magazine cover, described lawyers as "vampire" in a media interview, dressing up as Superman in printed advertisements, and demonstrated in central commercial area only wearing trunks (Chow, 2002; Nick 2006, 2008; Tsui 2009; Wong 2006). The case lucidly exhibits that lawyer as a professional is different from a businessperson or a movie star. Aggressive, undignified or "bad taste" promotional strategies are strongly discouraged. From the news report, we know that the Hong Kong legal community felt that they were offended by Mr. Tse's self-promotion and believed the public confidence in the lawyers hence would be prejudiced. 


\section{Cultural factors}

Hong Kong as a city where East meets West, the cultural dilemmas in handling conflict and dispute resolution may give us some hints on the societal background in which the lawyers is practiced (Chan, 2003; Lau \& Kuan, 1988). While the legal culture in Hong Kong is western-oriented, the distinctive ethos of the Hong Kong Chinese is a hybrid of Western acculturation, modern capitalist liberal spirit, localized pragmatism and continuation of traditional Chinese values (Lau \& Kuan, 1988; Law, 2009). Being a high context culture, Chinese people tend to be less confrontational and more likely to employ a relatively indirect-inactive way of dealing with conflict, such as avoiding or ignoring the conflict situation, or seeking compromise (Kirkbride, Tang, \& Westwood, 1991; Leung, 1988; Ma, 1992). On the contrary, people in lowcontext culture (e.g. North Americans) tend to adopt a direct-active stance toward conflict, and be more confrontational in disagreement (Ma, 1992; Ting-Toomey 1985). Hence, Americans are believed to be more likely to use confrontation and litigation to achieve their goals in settling of disputes. Chinese people show preference for mediation in resolving dispute (Goh, 2002; Leung, 1987). Mediation is preferred because it serves the multiple functions of repressing social conflicts, smoothing away discord and maintaining social relationships (Di and Wu, 2009).

Kirkbride, Tang, and Westwood (1991) point out that harmony, conformity, contextualism, guanxi, and face as the five most basic traditional Chinese cultural values that are relevant to conflict management behaviors. Collectivistic Chinese people's character of cherishing social harmony, adopting subtle communication to save face, obeying authority even to the extent of "fear of officialdom" are attributes to the tendency of avoiding court proceedings. The "litigation-averse" nature of Chinese societies (Goh, 2002) is best summarized by the well-known Chinese proverb "in death avoid hell, in life avoid law courts” (e.g. Utter 1990; Wong, 2010).

Although throughout Chinese history mediation has long been the favored way of handling disputes (Di \& Wu, 2009), Hong Kong people are also under the Western influence of perceiving law as a tool of protecting the rights of individuals. Survey results showed a belief in law as a foundation of prosperity and stability among interviewees. They valued the extent of liberties and civil rights they enjoyed and tend to support the protection of freedom as the major purpose of law (Lau \& Kuan, 1988). Under the concept of "one country, two systems", the community held faith in the independence and competence of the judiciary (Law Society of Hong Kong, 2007).

\section{Consumers' attitude towards advertising by lawyer's}

Academic research in the area of legal services advertising is under-explored in nonWestern countries. The only published study on the topic in Hong Kong measured consumers' attitude towards professional advertising in a general sense. A convenient sample survey was conducted just after the 1996 amendment. Results found that interviewee's general perception of professional advertising at that period was fairly positive (Au, 1997). Interviewees believed that advertising would not significantly affect the current favorable image enjoyed by doctors, accountants, and lawyers. They agreed that professional advertising increased their awareness of professionals and 
informed them about the nature and availability of services, as well as qualifications of professionals. However, interviewees were suspicious of professionals who advertise. Altogether 56 percent of interviewees did not agree that a greater use of advertising by professionals would improve the quality of their services. Along with 55 percent of interviewees worrying that prices would be increased because of the costs of advertising, 57 percent disagreed that when professionals advertise, prices would be lowered due to more competition.

Overall, Au's (1997) study showed that Hong Kong lawyers enjoyed a high image in the eyes of the public. Consumers not only believed that advertising would not cause any image problem for the lawyers, but it could also serve as a means for the community to acquire information about legal services. The only concern was whether the cost of legal services would be increased due to more advertising.

\section{Research objectives}

With the legality of advertising by lawyer's established and the standard effectively regulated, it is now the responsibility of the profession and of society to work out effective advertising implementation within which non-exploitative, trustful, and decent promotional activities could take place. In order to communicate effectively with consumers about legal services through advertising and other marketing activities, there is a need to understand consumers' attitudes and concerns about advertising by lawyer's. Advertisers should also need to know the types of information sought by consumers when designing messages. A study was conducted with the following research objectives:

- To examine perception of benefit and harm of advertising by lawyer's to individuals as well as to society;

- to investigate what information items are perceived by consumers as desirable or undesirable in advertising by lawyer's; and

- to examine perceived credibility of advertising by lawyer's in various advertising media.

\section{Methodology}

This study employed interviews. A qualitative methodology was justified because it allows for an exploratory examination of a phenomenon in which the relevant variables have yet to be identified (Wimmer \& Dominick, 1997). Because there has been no previous study on attitudes toward advertising by lawyer's in Hong Kong, interviewing was the preferred data collection method.

The interview opens with an introduction, "Some advertisements are about a specific profession. This will be the focus of our discussion today". Two television commercials of advertising by lawyer's were shown to the interviewees on a lap-top computer. The interviewees were asked about the perceived benefit and harm of advertising by lawyer's to consumers and society. Interviewees were asked to report types of information that advertising by lawyer's should have or should not have, and the reasons behind. Finally interviewees were asked to report on a medium that they find most trustworthy regarding where advertising by lawyer's are placed and the 
reasons for that opinion. The questions asked are listed in Appendix.

A convenience sample was adopted. The decision on sample size was guided by reference to the research interpretative framework and realistically by practicalities and logistic arrangement (Miles \& Huberman, 1994). The interviewees were 36 Chinese adults aged 20 to 44 recruited through personal networks. Twenty-two were females and 14 were males. Undergraduate students of the Hong Kong Baptist University served as the interviewers. The study was conducted in Cantonese in October 2010. The interviews were audio recorded and transcribed. Marshall and Rossman's (1999) comparison analysis method was used throughout the data analysis process to link data by constantly comparing and contrasting them (Strauss, 1987). The transcripts were analyzed question by question by two of the authors. A third author went through the coding and agreed with all the coding for questions 3 to 6 . Inter-coder reliability scores using Perreault and Leigh's (1989) measure for questions 1 and 2 were 0.98 and 0.92 respectively. Disagreements were resolved through discussion by three coders. Similar answers were grouped and frequencies were recorded. Because of the small sample size and the non-random sampling method, the results can only be considered exploratory. They were not, therefore, analyzed by age or sex.

\section{Findings}

\section{Perceived benefit of advertising by lawyer's}

A total of 76 answers about benefit of advertising by lawyer's were reported. These answers were grouped into 5 categories (see Table 1).

TABLE 1 Perceived Benefits of Advertising by Lawyer's

Frequency

Provide details about legal services: scope of services and fee structure 30

Help to find legal services more easily or to have more choices

Enhance the image of lawyers: more credible, more approachable, or 10 more transparent

Enhance public legal knowledge

Lead to better and cheaper legal services

Total*

* Interviewees can give more than one answers

The most frequently mentioned benefit of advertising by lawyer's was the information value of the advertisements. Interviewees specifically mentioned scope 
of services and fee structure as the information items provided by the advertisements. Two typical quotas are as follows:

"It provides more information about the available legal services. Consumers will be less panic, especially those who have never used such service before" (female, age 20-24).

"It gives a clear picture about the fee structure for the service. Consumers able to set their budget and expectation” (male, age 30).

The second most frequently mentioned benefit of advertising by lawyer's was that it would make the search of legal services providers more easily. In other words, the time and effort to find a suitable legal service provider would be reduced. A typical quote is as follows:

"With advertising by lawyer's, it is much easier for people to find a lawyer than before. It saves time as well as effort” (female, age 20-24).

At the same time, some interviewees thought that advertising by lawyer's provided them with more choices. One interviewee even commented that it set an example for other professions to follow.

The third most frequently mentioned benefit of advertising by lawyer's was enhancing the image of the lawyers. Typical comments include "it makes the lawyers more approachable to the general public", "I have more confidence on the legal services when they advertise" and "Law firms with ads are stronger financially and should be more trustworthy". Other interviewees reported that with legal services advertisements, they found the lawyers more transparent, as well as more acceptable. Other perceived benefits of advertising by lawyer's include enhancing public legal knowledge or leading to better /cheaper service. For example, an interviewee commented that "Advertising by lawyer's provide people with more legal knowledge. If I have a traffic accident, I know I can find some lawyers to deal with the case. It gives me peace of mind".

\section{Perceived harm of advertising by lawyer's}

A total of 58 answers about the harm of advertising by lawyer's were reported. These answers were grouped into 5 categories (see Table 2). 
TABLE 2 Perceived Harms of Advertising by Lawyer's

Frequency

Advertisements contain exaggerated or misleading information

Damage the image of lawyers: greedy, cunning, not-trustworthy, or ${ }_{16}$ unscrupulous

Encourage people to solve problems by litigation

Increase the cost of legal services

Lead to oligopoly or poor service because of unhealthy competition

Total*

*Interviewees can give more than one answers

The most frequently mentioned harm of advertising by lawyer's was that advertising by lawyer's contained exaggerated or misleading information.

"Many advertising by lawyer's on TV are misleading. For instance, the advertisement states that the service fee is only HK\$888. I believe that there must be a lot of hidden costs" (male, age 34).

The second most frequently mentioned harm of advertising by lawyer's was that it would damage the image of lawyers. Two typical quotes are given below:

"It gave me a feeling that lawyers are encouraging people to take legal proceedings in order to earn more money. They were money-hungry and were therefore not trustworthy" (female, age 30-34).

“Advertising by lawyer's deteriorate the profession's image. They are only interested to deal with small problems such as divorce or personal financing. They are too commercialized" (females, age 20-24).

The third most frequently mentioned harm of advertising by lawyer's was that these advertisements would encourage people to solve problems by litigation. Some comments were more general, such as "too many law ads lead to too many lawsuits. That leads to pessimism”. Some comments were more specific. Divorce and personal finance were identified as scope of legal service that might be over-used. Two typical comments are quoted here. "Sometime law ads advocated divorce cases and spelt out that high alimony could be obtained. This would increase divorce rate. It educates people that divorce is easy and you may get a high alimony out of it", "Personal financing service would lead to more problematic loans. People would think that there was always an easy way out”. 


\section{Desirable and undesirable information in advertising by lawyer's}

Regarding information items that advertising by lawyer's should have, altogether 91 information items were reported. The top three information items were contact information, scope of service, as well as service fees. Interviewees were most interested in getting company contact information such as phone number, address and website. Interviewees reported that this information helps them to assess the strength of the company. Here is a typical quote:

"...I want to know how big the company is, how many lawyers are working there, how many branches the company has, etc....from that I can tell whether they are trustworthy or not" (female, age 24).

Following contact information, interviewees were keen to know the scope of service provided by the law firms. They also wanted to know whether a law firm was specialized in certain types of legal services, such as divorce, work injury compensation or personal finance.

The third most frequently reported desirable information item was the fee structure. Interviewees were eager to know how the legal services would be charged. As the service charge was not always explicitly stated in the advertisements, some interviewees worried that the actual service fees could be far beyond what they expect. Here is a typical quote:

“... it would be good if the ad could state the fee explicitly. Lawyers consultation is not cheap...so consumers should at least know how and what to budget” (male, age 37).

Other desirable information items included qualifications of the lawyers. Some interviewees believed that different law firms would have different strength. Advertising should therefore focus on their own expertise. Besides, interviewees were interested to know about the qualifications of individual lawyers. They perceived that the longer the working experience of a lawyer, the more credible and trustworthy he/she will be.

Regarding information items that advertising by lawyer's should not have, altogether 49 information items were reported. The top three information items were exaggerated/misleading/inaccurate information, service fees and superlative claims. Results indicated that interviewees perceived that descriptions such as "unbeatable prices", "commission-free guarantee" or "all-inclusive package-fee" in the advertising by lawyer's were deemed to be misleading.

Some interviewees suggested not including service fees in the advertisements because it would degrade the professional image of lawyers. For those advertisements that emphasized low service fees, interviewees found them deceptive as interviewees did not believe that a fixed cost would apply to all consumers.

Superlatives in advertising such as 'the best', 'guarantee', 'sure win', and 'the cheapest' were also unwelcomed by the interviewees. Other information items 
perceived as undesirable in advertising by lawyer's included criticism of competitors and successful rates of legal proceedings. Interviewees commented that advertising by lawyer's should not bad-mouth competitors. As there is no guarantee of winning in a lawsuit, claiming 100 percent success rate was perceived to be incredible by interviewees. Four interviewees mentioned that advertising by lawyer's should not focus on individual lawyers. They believed that focusing too much on one individual would over-shadow the contribution of the whole team of lawyers in the same company. Besides, self-promotion was perceived to be too hard-sell. Mr. Paul Tse Wai-chun's self-promotion was brought up by two interviewees. Both of them condemned his promotional gimmicks as unprofessional and weird.

TABLE 3 Desirable and Undesirable Information in Advertising by Lawyer's

\begin{tabular}{ll}
\hline Information items & Frequency \\
\hline desirable & 29 \\
contact information & 27 \\
scope of service & 16 \\
service fees & 13 \\
unique service/expertise & 6 \\
professional qualifications & 91 \\
total & \\
& \\
undesirable & 24 \\
exaggerated/misleading/inaccurate information & 8 \\
service fees & 5 \\
superlative claims & 4 \\
criticism on direct competitors & 4 \\
successful cases/portfolios & 4 \\
self-promotion & 49 \\
total &
\end{tabular}

\section{Most as well as least credible media for placing advertising by lawyer's}

Regarding the most credible media for advertising by lawyer's, interviewees perceived television as the most credible medium, followed by newspapers, and magazines. The reported frequencies were 24,11 , and 4 respectively (see Table 4 ).

TV was perceived as the most credible media for advertising by lawyer's because of two reasons. First, the cost for producing television commercials was perceived to be high. As a result, many interviewees believed that only successful and reputable companies could afford it. Second, TV commercials were perceived to be more credible because they were scrutinized by the government authority.

Regarding the least credible media for placing advertising by lawyer's, interviewees perceived television as the least credible medium, followed by newspapers, and the Internet. The reported frequencies were 10, 8, and 7 respectively (see Table 4). Television commercials were perceived to be least credible because interviewees 
found them "too dramatic”, or "placing too much emphasis of slogans”.

TABLE 4 Advertising Media Perceived to be the Most or the Least Credible

\begin{tabular}{|c|c|c|c|}
\hline Advertising Media & $\begin{array}{ll}\begin{array}{l}\text { Most } \\
\text { (frequency) }\end{array} & \text { credible } \\
\end{array}$ & $\begin{array}{l}\text { Least } \\
\text { (frequency) }\end{array}$ & credible \\
\hline TV & 24 & 10 & \\
\hline Newspaper & 11 & 8 & \\
\hline Magazine & 4 & 2 & \\
\hline Out-of-home & 2 & 6 & \\
\hline Radio & 2 & 2 & \\
\hline Online/Internet & 1 & 7 & \\
\hline Direct mailing & 0 & 4 & \\
\hline Others/Not mentioned & 4 & 3 & \\
\hline Total* & 48 & 42 & \\
\hline
\end{tabular}

* Interviewees can give more than one answer

Newspaper advertising by lawyer's were perceived to be less credible because of the small size, unappealing messages, or the placing of advertising by lawyer's together with consumer products advertisements. Online/Internet advertising by lawyer's was perceived to be less credible mainly because of a general mistrust of the Internet as an advertising medium.

\section{Discussion}

In this qualitative study, researchers asked thirty-six interviewees aged 20 to 44 in Hong Kong about their views on advertising by lawyer's. Based on the interviews, we have the following five observations about consumers' attitudes toward advertising by lawyer's.

First, interviewees appreciated the information values of advertising by lawyer's. This finding is consistent with a previous study that consumers believed it is proper for professionals (including accountants, doctors, and lawyers) to advertise because consumers can obtain useful information from the advertisements ( $\mathrm{Au}, 1997)$. As most of the interviewees were interested in basic information such as contacts, scope of services, and fee system, it suggests that most of the interviewees have insufficient knowledge about the availability and practices of the lawyers in Hong Kong. This is understandable given the low number of lawyers in the population (0.7 lawyers per 1000 population). Also, a majority of the law firms are located in the Central District on the Hong Kong Island and are physically remote from the residential areas. This makes the lawyers out of touch with the general public (Chan, 2012). Providing information is one of the basic functions of advertising and it is particularly important for high-involvement products and services. Legal service is undoubtedly a high involvement service and as a result, consumers need to have in-depth information about it before making a purchase decision. Another perceived function of advertising by lawyer's is to reduce consumers' time and cost in locating an appropriate legal services provider. Interviewees perceived that advertising by lawyer's can inform 
them under what situations they can seek advice from lawyers. This also suggests that interviewees are not familiar with their legal rights.

Second, together with the heavy reliance on advertising for information about legal services, interviewees placed great emphasis on the accuracy and validity of the information provided in the advertisements for legal services. This can be seen repeatedly in as much as interviewees worry about misleading information in the advertisements as well as the fact that exaggerated and false claims were most frequently reported as undesirable information in the advertisements. Service fee is a controversial information item among the interviewees. On one hand, they would like to know how the legal services are charged. On the other hand, they perceived an allinclusive package charge or the low charging fee unreliable. This is probably because legal services are extremely complicated and the charging fees are expected to differ significantly from case to case.

Third, there were diverse views about the impact of advertising by lawyer's on the image of the lawyers. A previous quantitative study found that professionals in Hong Kong enjoyed a high image, and that consumers did not believe advertising would lower the favorable image enjoyed by professionals (Au, 1997). The result of our study was somewhat different from Au's (1997) study. There were more interviewees expressing the view that advertising by lawyer's damage the favorable image of the profession than the view that these advertisements elevate the image of the profession. As these two studies differed much in the coverage of professionals, the research methodology, as well as time of the study, direct comparison of findings was inappropriate. However, our finding suggests that the lawyers may suffer from a deterioration of image if advertising by lawyer's are presented in a way that is not acceptable by consumers. Furthermore, interviewees were concerned that advertising by lawyer's may encourage people to use litigation as problem solving.

Fourth, interviewees held strong belief in price-quality association for legal services. Interviewees did not believe that quality legal services come with a rock bottom price. They expressed that they would rather pay more to enjoy a quality service than a cheap and unprofessional one. The perceived importance of quality of service and the reputation of lawyers was similar to that expressed by US consumers in a previous study (Moser, 2005). Interviewees associated low price with ineffective services. As an old Chinese saying said "the cheap buyer takes bad meat". Advertisers of legal services should bear in mind consumers' deep-rooted beliefs and should not attract customers merely using price appeal.

Fifth, interviewees believed strongly in specialization of legal services and team work in providing quality legal services. Interviewees were interested to know about the expertise of individual law firms. They also wanted to see advertisements about the whole company, instead of focusing on one or two individual lawyers. This finding can be attributed to two reasons. First, Hong Kong is a collectivist society. People believe in group success rather than individual success. As a result, they found advertising by lawyer's that focused on a single lawyer unacceptable. Second, interviewees were affected negatively by Paul Tse Wai-chun's self-promotion case. Several interviewees reported that they did not want to see similar advertisements again. 


\section{Conclusion}

A qualitative study was conducted to investigate Hong Kong consumers' attitudes toward advertising by lawyer's. The study found that consumers in general appreciated the information value of these advertisements. There were mixed views of the impact on the image of the lawyers of advertising by lawyer's. Some interviewees found the advertisements helpful and hence perceived that the lawyers was more approachable and transparent. However, some interviewees found advertising by lawyer's that use price appeal misleading. They perceived lawyers to have become more commercialized. Interviewees expressed concern that advertising by lawyer's encourage the seeking of litigation as a preferred way of problem solving. The study informs lawyers regarding message design and media selection in the marketing of their services.

Based on the current study, we have the following recommendations for lawyers in marketing their services through advertising. First, advertising by lawyer's should contain key information, such as scope of service, expertise, and contact information. The advertisements should highlight the unique services offered by the firm. Second, lawyers should be sensitive in presenting price or fee information. They should not solely use price as an appeal to attract consumers. Exceptional low price or price guarantees will be perceived as misleading by consumers. We recommend that the fee system should be presented in a transparent and credible manner. Third, as Chinese culture puts much emphasis on social harmony, aggressive promotion of legal services could damage the image of the lawyers. We suggest that advertising by lawyer's might encourage potential consumers to seek other problem solving channels before they consider legal action as a kind of disclaimer, or as a gesture toward corporate social responsibility. Fourth, advertising by lawyer's should communicate the expertise of the law firm's whole team of lawyers, and should not focus on individual lawyers. Fifth, lawyers should use a media mix in communicating their services. Television advertisements can be used to reach a wide range of consumers for awareness while print advertisements can be used to explain details of services.

\section{References}

admanGo. (2011). Advertising expenditure by product category in 2010. Retrieved from www.admanGo.com. (by subscription).

Au, A. K. M. (1997). Consumers' attitudes towards professional advertising in Hong Kong. Services Marketing Quarterly, 15(2), 41-53.

Brosnahan, R. P., \& Andrews, L. B. (1980). Regulation of lawyer advertising: In the public interest? Brooklyn Law Review, 46, 423-436.

Burton, G. E. (1991). Attitudes toward the advertising by lawyers, doctors, and CPA's. Services Marketing Quarterly, 8(1), 115-127. 
Chan, C. L. W. (2003). The cultural dilemma in dispute resolution: The Chinese experience. Presentation at the Conference of Enforcing Equal Opportunities in Hong Kong: An Evaluation of Conciliation and Other Enforcement Powers of the EOC, Centre for Comparative and Public Law, Faculty of Law, University of Hong Kong, Hong Kong, June 14, 2003.

Chan, K. (2006). Advertising and Hong Kong society. Hong Kong: The Chinese University Press.

Chan, K. (2012). Advertising for the legal professionals: Interview with Ka Kin Lau, Reed Smith Richards Butler [DVD]. Hong Kong: Hong Kong Baptist University.

Chow, M. (2002, September 12). Lawyer loses challenge to secret probe. South China Morning Post, pp. 6.

Court of Final Appeal Hong Kong SAR. (2008). A Solicitor Vs Law Society of Hong Kong, March $13 \quad 2008.2$ Retrieved from http://www.ipsofactoj.com/international/2008/Part01/int2008(01)-004.htm

Crane, F. G. (1995). Consumers' and lawyers' attitudes toward legal services advertising in Canada. Services Marketing Quarterly, 13(1), 65-70.

Cutler, B., Javalgi, R., \& Schimmel, K. (2003). Advertising as a cause of bias in American juries: An exploratory study. Journal of Marketing Communications, 9(3), 163-175.

Di, X., \& Wu, Y. (2009). The developing trend of the people's mediation in China. Sociological Focus, 42(3), 228-245.

Ellis, N., \& Watterson, C. (2001). Client perceptions of regional law firms and their implications for marketing management. The Service Industries Journal, 21(4), 100118.

Goh, B. C. (2002). Law without lawyers, justice without courts: On traditional Chinese mediation. Aldershot, UK: Ashgate.

Hofer, R. E. (2010). Lawyer advertising bates revisited. Experience Magazine, 20(1), 4, 3739.

Johnson, K. O. (2004). Walking the advertising tightrope: A delicate balance. The Florida Bar Journal, 78(11), 5-6.

Johnson, M., Yazdi, K., \& Gelb, B. D. (1993). Attorney advertising and changes in the demand for wills. Journal of Advertising, 22(1), 35-45.

Kallis, M. J., \& Vanier, D. J. (1983). Consumer perceptions of attorney and legal service advertising: A managerial approach to the delivery of legal services. Akron Business and Economic Review, 14(4), 42-47.

Kirkbride, P. S., Tang, S. F. Y., \& Westwood, K. I. (1991). Chinese conflict preferences and negotiating behaviour: Cultural and psychological influences. Organization Studies, 12(3), 365-386.

Lau, S. K., \& Kuan, H. C. (1988). The ethos of the Hong Kong Chinese. Hong Kong: The Chinese University Press. 
Law Society of Hong Kong. (2007). Celebrating a centenary: The Law Society of Hong Kong 1907-2007. Hong Kong: The Standard Newspapers Publishing Ltd.

Law, W. S. (2009). Collaborative colonial power: The making of the Hong Kong Chinese. Hong Kong: Hong Kong University Press.

Leung, K. (1987). Some determinants of reactions to procedural models for conflict resolution: A cross-national study. Journal of Personality and Social Psychology, 53(5), 898-908.

Leung, K. (1988). Some determinants of conflict avoidance. Journal of Cross-cultural Psychology, 19(1), 125-136.

Love, J. H., \& Stephen, F. H. (1997). Deregulation and professional boundaries: Evidence from the English legal profession. Business and Economic History, 26(2), 792-804.

Ma, R. (1992). The role of unofficial intermediaries in interpersonal conflicts in the Chinese culture. Communication Quarterly, 40(3), 269-278.

Marshall, C., \& Rossman, G. B. (1999). Designing qualitative research (3rd ed.).

CA: Sage.

McCann, M., Stem, D. E. Jr., \& Muehling, D. D. (1993). Attorneys' attitudes toward legal advertising: A longitudinal view. Services Marketing Quarterly, 8(2), 157-176.

Miles, M. B. \& Huberman, A. M. (1994). Qualitative data analysis (2nd ed.). Thousand Oaks, CA: Sage.

Moser, H. R. (2005). An empirical analysis of consumers' attitudes toward legal services advertising. Services Marketing Quarterly, 26(4), 39-56.

Moser, H. R., \& Johns, H. E. (1996). An empirical analysis of consumers' attitudes toward attorney advertising. Services Marketing Quarterly, 15(1), 85-104.

Nick, G. (2006, July 8). Unacceptable conduct' ruling for solicitor upheld. South China Morning Post, pp. 3.

Nick, G. (2008, March 14). Lawyer fails to overturn ban for posing nude: Naked shots may spur Legco bid. South China Morning Posts, pp. 5.

Perreault, W. D., Jr., \& Leigh, L. E. (1989). Reliability of nominal data based on qualitative judgments. Journal of Marketing Research, 26(2), 135-148.

Smith, R. E., \& Meyer, T. S. (1980). Attorney advertising: A consumer perspective. Journal of Marketing, 44(2), 56-64.

Strauss, A. L. (1987). Qualitative analysis for social scientists. MA: Cambridge University Press.

Traylor, M. B., \& Mathias, A. M. (1983). The impact of TV advertising versus word of mouth on the image of lawyers: A projective experiment. Journal of advertising, 12(4), 4249. 
The Law Society of Hong Kong. (2011a). About the Society, No.7 Profile of the Profession. Retrieved from http://www.hklawsoc.org.hk/pub_e/about/

The Law Society of Hong Kong. (2011b). Professional Guide, Vol. 2, The Hong Kong Solicitors' Guide to Professional Conduct. Retrieved from http://www.hklawsoc.org.hk/pub_e/professionalguide/volume1/default.asp

Ting-Toomey, S. (1985). Toward a theory of conflict and culture. In W. B. Gudykunst, L. P. Stewart \& S. Ting-Toomey (Eds.), International and intercultural communication annual: Communication, culture, and organizational Processes (Vol. 9, pp. 71-86). Beverly Hills, CA: Sage.

Tsui, Y. (2009, November 4). Lawyer wins bid for judicial review of process that suspended him. South China Morning Post, pp. 3.

Utter, R. (1990). Dispute Resolution in China. Family Court Review, 28(1), 65-70.

Williams, V. (1998, August). Advertising: Does it pay? Hong Kong Lawyer, pp. 33-38.

Wimmer, R. D., \& Dominick, J. R. (1997). Mass media research: An introduction

(5th ed.). Belmont, CA: Wadsworth.

Wong, A. (2006, February 24). 'Naked crusader' in fight over $\$ 7 \mathrm{~m}$ bill. The Standard. Retrieved from http://www.thestandard.com.hk/news_print.asp?art_id=12762\&sid=6802333

Wong, Y. L. (2010). Mediation and medical practice. Arthur Li Oration at the Conjoint Diploma Conferment Ceremony at the College of Surgeons of Hong Kong by the Secretary for Justice Hon; Hong Kong, September 25, 2010.

\section{Appendix List of questions asked}

What would you say about the benefits of advertising by lawyer's to consumers and the society?

What would you say about the problems or harms of advertising by lawyer's to consumers and the society?

What types of information or messages do you think the advertising by lawyer's should have?

What types of information or messages do you think the advertising by lawyer's should NOT have?

What is the most credible/trustworthy advertising medium for placing advertising by lawyer's? Why?

What is the least credible/trustworthy advertising medium for placing advertising by lawyer's? Why? 